\title{
Musculus Latissimus Dorsi
}

National Cancer Institute

\section{Source}

National Cancer Institute. Musculus Latissimus Dorsi. NCI Thesaurus. Code C33150.

A triangular muscle in the back, connected to the vertebral column, arm, and shoulder. Its action involves adduction, medial rotation, and extension of the arm. 